\title{
Fluoroalkyl end-capped oligomers possessing nonflammable and flammable characteristics in silica gel matrices after calcination at $800{ }^{\circ} \mathrm{C}$ under atmospheric conditions
}

\author{
Hideo Sawada $^{1}$, Tsukasa Tashima ${ }^{1}$, Hiroshi Kakehi ${ }^{1,2}$, Yusuke Nishiyama ${ }^{3}$, Mieko Kikuchi ${ }^{1}$, Masashi Miura ${ }^{2}$, \\ Yusuke Sato $^{2}$ and Norifumi Isu ${ }^{2}$ \\ Fluoroalkyl end-capped $\mathrm{N}$-(1,1-dimethyl-3-oxobutyl)acrylamide oligomer $\left[\mathrm{R}_{\mathrm{F}}-(\mathrm{DOBAA})_{\mathrm{n}}-\mathrm{R}_{\mathrm{F}}\right]$ in silica nanocomposite can exhibit a \\ nonflammability, even after calcination at $800^{\circ} \mathrm{C}$, through the formation of ammonium hexafluorosilicate during nanocomposite \\ reactions. In contrast, the lack of formation of ammonium hexafluorosilicate during the usual composite reactions affords a \\ flammable behavior for the $R_{F}-(D O B A A)_{n}-R_{F}$ oligomer in silica nanocomposite. Ammonium hexafluorosilicate is formed as a \\ result of the dehydrofluorination of amido protons $[-C(=0) N H-]$ in $R_{F}-(D O B A A)_{n}-R_{F}$ oligomer, with fluorine atoms in the oligomers \\ catalyzed by both ammonia and silica nanoparticles in the composite reactions. In contrast, the lack of dehydrofluorination in \\ the nanocomposite reaction under acidic conditions affords the usual flammable behavior for the oligomer. \\ Polymer Journal (2010) 42, 167-171; doi:10.1038/pj.2009.316; published online 23 December 2009
}

Keywords: calcinations; fluorinated oligomer; nonflammability; silica nanocomposite; thermostability

\section{INTRODUCTION}

Traditional organic polymers, such as poly(vinyl chloride), poly(ethylene), poly(propylene) and poly(styrene), are well known for decomposing completely at around $400-500^{\circ} \mathrm{C}$. However, perfluorinated polymers such as poly(tetrafluoroethylene) decompose at higher temperatures (around $600{ }^{\circ} \mathrm{C}$ ) because of the bond-strengthening effect of fluorine for the $\mathrm{C}-\mathrm{C}$ and $\mathrm{C}-\mathrm{F}$ bonds in highly fluorinated compounds. ${ }^{1-5}$ From the developmental viewpoint of novel nonflammable materials, hybridizations of these fluorinated polymers with metal alkoxides ${ }^{6-10}$ and graphite oxide ${ }^{11}$ are of particular interest. In fact, some studies on the hybridization of fluorinated polymers with alkoxysilanes $^{6-10}$ have been hitherto reported; however, the thermal stability of these hybrids is in general inferior to that of the original silica gels. ${ }^{6-10}$ In this study, we report that fluoroalkyl end-capped $\mathrm{N}$-(1,1-dimethyl-3-oxobutyl)acrylamide oligomer $\left[\mathrm{R}_{\mathrm{F}}-(\mathrm{DOBAA})_{\mathrm{n}}-\mathrm{R}_{\mathrm{F}}\right]$ in silica nanocomposite can exhibit a nonflammability, even after calcination at $800^{\circ} \mathrm{C}$, through the formation of ammonium hexafluorosilicate during nanocomposite reactions. In contrast, the lack of formation of ammonium hexafluorosilicate during the usual composite reactions affords a flammable behavior for $R_{F^{-}}(D O B A A)_{n}-R_{F}$ oligomer in silica nanocomposite.

\section{EXPERIMENTAL PROCEDURE}

Methods

Measurements. ${ }^{19} \mathrm{~F}$ magic-angle spinning (MAS) nuclear magnetic resonance (NMR) spectra were measured at room temperature using a JEOL JNMECA500 spectrometer with a $3.2 \mathrm{~mm}{ }^{19} \mathrm{~F}$ MAS probe (Jeol, Tokyo, Japan). Fourier transform-infrared (FT-IR) spectra were measured using a Shimadzu FTIR-8400 FT-IR spectrophotometer (Kyoto, Japan). Molecular weights of the fluorinated oligomers were measured using Shodex DS-4 (pump) and Shodex RI-71 (detector) gel permeation chromatography (Tokyo, Japan), calibrated with a polystyrene standard and using tetrahydrofuran (THF) as the eluent. Thermal analyses were recorded by raising the temperature to around $800{ }^{\circ} \mathrm{C}$ (with a heating rate of $10^{\circ} \mathrm{C} \mathrm{min}^{-1}$ ) under atmospheric conditions by the use of a Bruker axs TG-DTA2000SA differential thermobalance (Bruker AXS, Kanagawa, Japan). Dynamic light scattering (DLS) was measured using the Otsuka Electronics DLS-7000 HL (Otsuka Electronics, Tokyo, Japan).

Preparation of fluoroalkyl end-capped N-(1,1-dimethyl-3oxobutyl)acrylamide oligomer/silica gel nanocomposite A methanol solution $(20 \mathrm{ml})$ of fluoroalkyl end-capped $\mathrm{N}$-(1,1-dimethyl3-oxobutyl)acrylamide oligomer $\left\{\mathrm{R}_{\mathrm{F}}-\left[\mathrm{CH}_{2} \mathrm{CHC}(=\mathrm{O}) \mathrm{NHCMe}_{2} \mathrm{CH} 2 \mathrm{C}(=\mathrm{O}) \mathrm{Me}\right]_{n}-\mathrm{R}_{\mathrm{F}}\right.$ $\left.\left[\mathrm{R}_{\mathrm{F}}-(\mathrm{DOBAA})_{\mathrm{n}}-\mathrm{R}_{\mathrm{F}}\right] ; \mathrm{R}_{\mathrm{F}}=\mathrm{CF}\left(\mathrm{CF}_{3}\right) \mathrm{OC}_{3} \mathrm{~F}_{7} ; M_{\mathrm{n}}=3710(0.50 \mathrm{~g})\right\}$, which was prepared by the reaction of fluoroalkanoyl peroxide with the corresponding

${ }^{1}$ Department of Frontier Materials Chemistry, Graduate School of Science and Technology, Hirosaki University, Bunkyo-cho, Hirosaki, Japan; ${ }^{2}$ INAX Corporation, R \& D Center, Tokoname, Aichi, Japan and 3JEOL Ltd, Akishima, Tokyo, Japan

Correspondence: Professor H Sawada, Department of Frontier Materials Chemistry, Hirosaki University, 3 Bunkyo-cho, Hirosakai 036-8561, Japan.

E-mail: hideosaw@cc.hirosaki-u.ac.jp

Received 14 July 2009; revised 6 September 2009; accepted 7 September 2009; published online 23 December 2009 

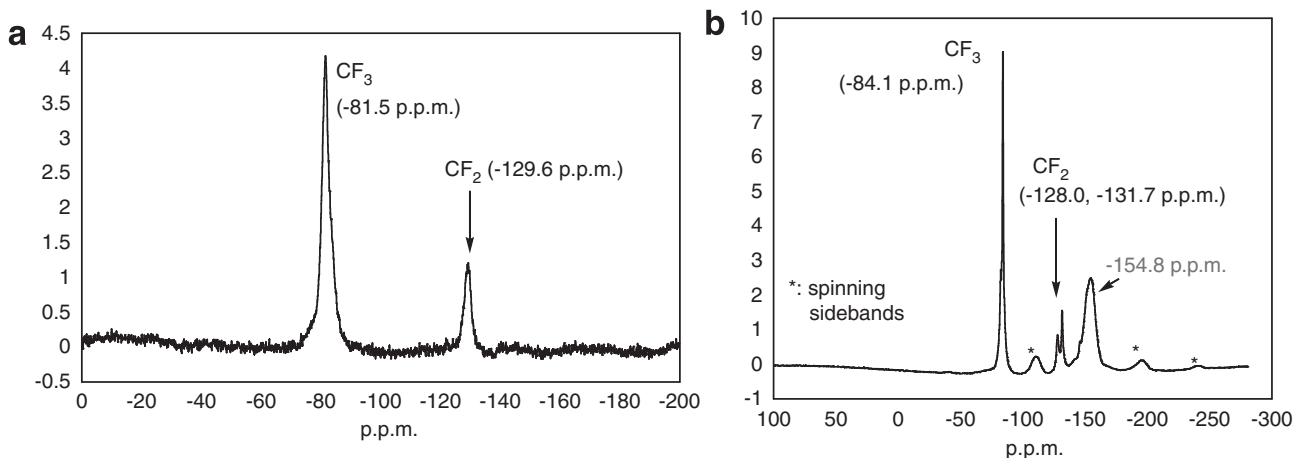

Figure $1{ }^{19} \mathrm{~F}$ Magic-angle spinning (MAS) nuclear magnetic resonance (NMR) spectra of $\mathrm{R}_{\mathrm{F}}-(\mathrm{DOBAA})_{\mathrm{n}}-\mathrm{R}_{\mathrm{F}} / \mathrm{SiO}_{2}$ composites possessing no weight loss characteristic (b) and weight loss characteristic (a) before calcination at $800^{\circ} \mathrm{C}$ determined by $3.2 \mathrm{~mm}{ }^{19} \mathrm{~F}$ MAS probe.

a

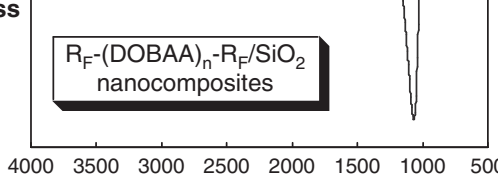

C

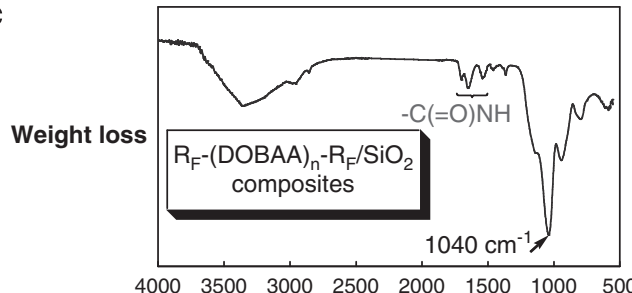

b

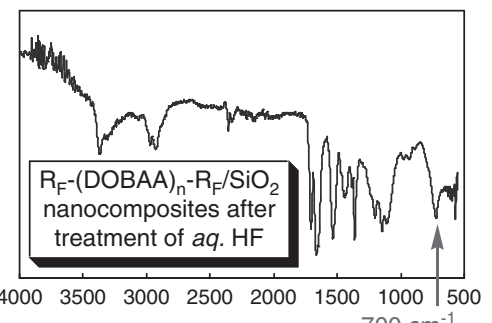

$4000350030002500200015001000 \quad 500$

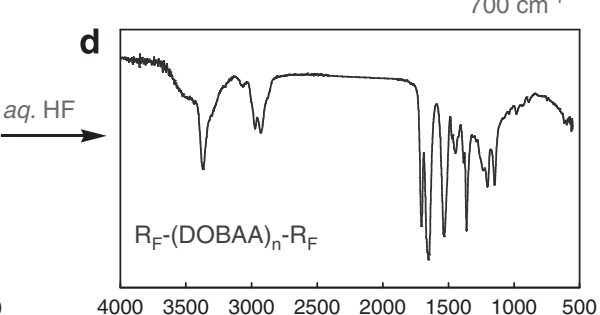

Figure 2 Fourier transform-infrared (FT-IR) spectra of $R_{F}-(D O B A A)-R_{F} / S_{i} O_{2}$ composites before and after the treatment with aqueous hydrogen fluoride (HF).

a
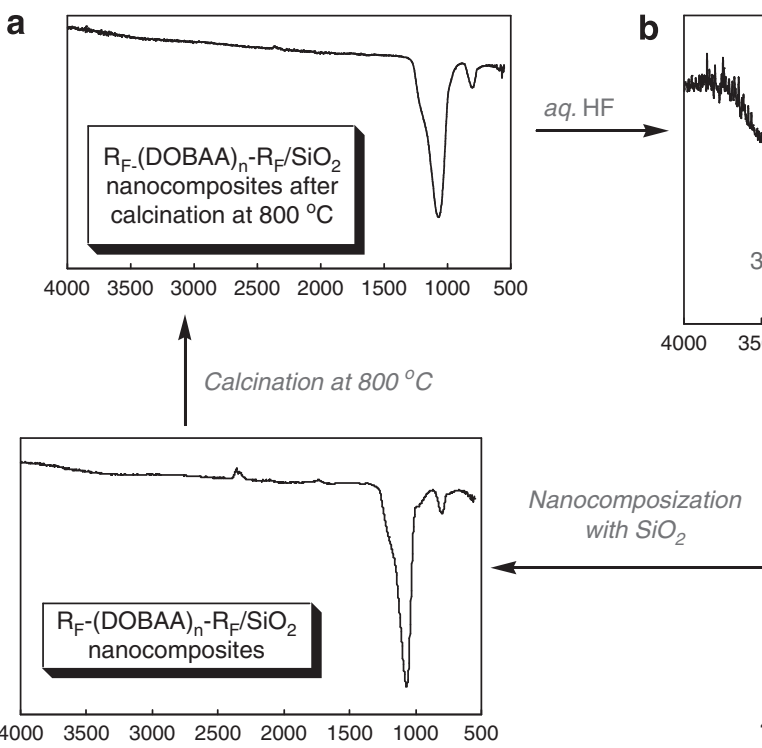

Figure 3 Fourier transform-infrared (FT-IR) spectra of parent $R_{F}-(D O B A A)_{n}-R_{F}$ oligomer, $R_{F}-(D O B A A)_{n}-R_{F} / S_{i O} O_{2}$ nanocomposites before and after calcination, and calcinated $\mathrm{R}_{\mathrm{F}}-(\mathrm{DOBAA})_{n}-\mathrm{R}_{\mathrm{F}} / \mathrm{SiO}_{2}$ nanocomposites after the treatment with aqueous hydrogen fluoride (HF). 


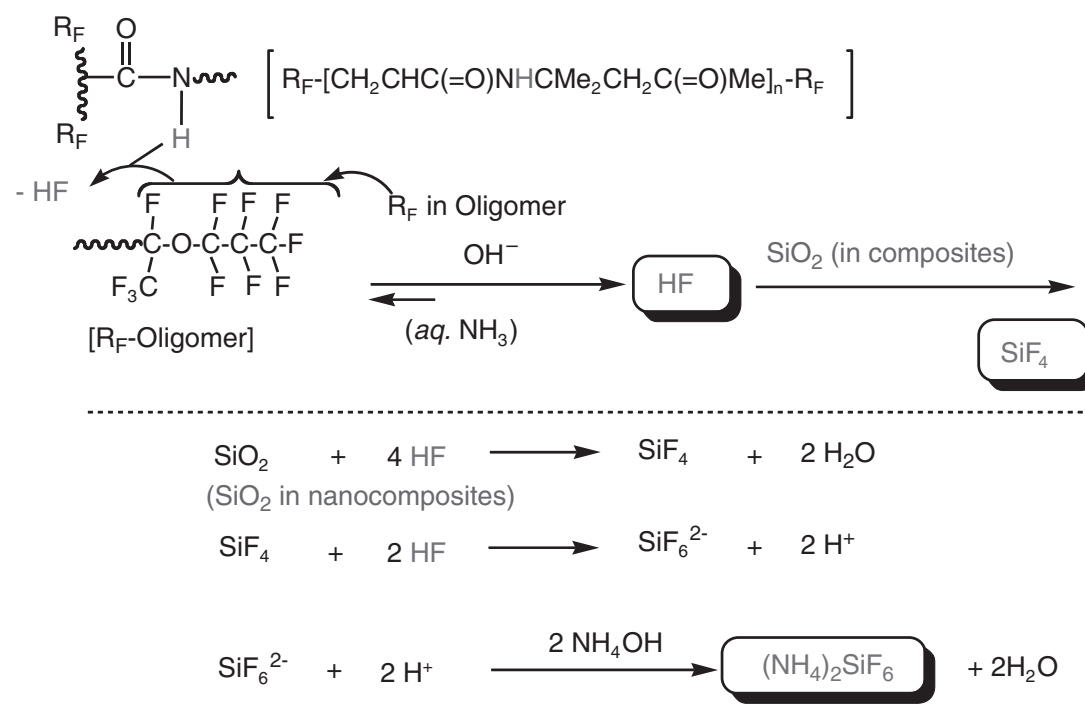

Scheme 2 Plausible mechanism for the formation of ammonium hexafluorosilicate.

Table 1 Thermal stability of a variety of fluoroalkyl end-capped oligomers/silica composites under atmospheric conditions $\left[R_{F}=C F\left(C F_{3}\right) O C_{3} F_{7}\right]$

\begin{tabular}{|c|c|c|c|}
\hline Oligomer in composite & Synthetic conditions & Size of composite, $n m$ (after calcination, $\mathrm{nm}$ ) & Weight loss (\%) at $800^{\circ} \mathrm{C}$ \\
\hline$\left.R_{F}-(D O B A A)\right)_{n}-R_{F}$ & Acidic condition & 359 & $25^{\mathrm{b}}$ \\
\hline$\left.R_{F}-(N I P A M)\right)_{n}-R_{F}$ & Acidic condition & 1500 & 13 \\
\hline$R_{F}-(D M A A)_{n}-R_{F}{ }^{d}$ & Alkaline condition & 46 & 8 \\
\hline$R_{F}-(D M A A)_{n}-R_{F}$ & Acidic condition & 431 & 32 \\
\hline$R_{F}-(M E S)_{n}-R_{F}^{f}$ & Alkaline condition & $51(45)$ & 0 \\
\hline$R_{F}-(M E S)_{n}-R_{F}$ & Acidic condition & 685 & 15 \\
\hline$R_{F}-(M A C A)_{n}-R_{F} g$ & Alkaline condition & 26 & 9 \\
\hline$R_{F}-(M A C A)_{x}-(T F M A)_{y}-R_{F}^{h}$ & Alkaline condition & $16(35)$ & 0 \\
\hline$R_{F}-(A C A)_{n}-R_{F}^{i}$ & Alkaline condition & 31 & $26^{\mathrm{j}}$ \\
\hline$R_{F}-(A M P S)_{n}-R_{F}^{k}$ & Alkaline condition & 31 & 26 \\
\hline
\end{tabular}

${ }^{a} R_{F}-(D O B A A) n-R_{F}: R_{F}-\left[C H_{2}-C H C(=0) N_{C H C}{ }_{2} C H_{2} C(=0) M e\right]_{n}-R_{F} ; M_{n}=10090$.

bee Sawada et al. ${ }^{13}$

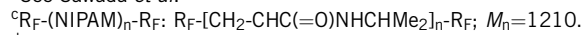

${ }^{d} R_{F}-(D M A A)_{n}-R_{F}: R_{F}-\left[C_{2}-C H C(=0) N_{2} e_{2}\right]_{n}-R_{F} ; M_{n}=1690$.

${ }^{e} \mathrm{R}_{\mathrm{F}}-(\mathrm{ACMO})_{\mathrm{n}}-\mathrm{R}_{\mathrm{F}}: \quad \mathrm{R}_{\mathrm{F}}-\left(\mathrm{CH}_{2}-\mathrm{CH}\right)_{\mathrm{n}}-\mathrm{R}_{\mathrm{F}}$

${ }^{f} R_{F}-(M E S)_{n}-R_{F}: R_{F}-\left[C H_{2}-C M e C(=0) O C_{2} C_{2} \mathrm{CH}_{2} \mathrm{SO}_{3} H\right]_{n}-R_{F} ; M_{n}=30000$.

$\mathrm{gR}_{\mathrm{F}}-(\mathrm{MACA})_{n}-\mathrm{R}_{\mathrm{F}}: \mathrm{R}_{\mathrm{F}-}\left[\mathrm{CH}_{2}-\mathrm{CMeC}(=\mathrm{O}) \mathrm{OH}\right]_{\mathrm{n}}-\mathrm{R}_{\mathrm{F}} ; M_{\mathrm{n}}=2740$.

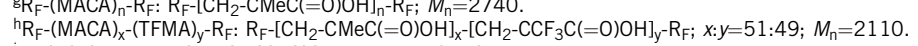

i $\mathrm{R}_{\mathrm{F}}-(\mathrm{ACA})_{\mathrm{n}}-\mathrm{R}_{\mathrm{F}}: \mathrm{R}_{\mathrm{F}}-\left[\mathrm{CH}_{2}-\mathrm{CHC}(=0) O H\right]_{\mathrm{n}}-\mathrm{R}_{\mathrm{F}} ; M_{\mathrm{n}}=2770$.

jSee Ansari and Giannelis. ${ }^{11}$

${ }^{k} R_{F}-(A M P S)_{n}-R_{F}: R_{F}-\left[C_{2}-\mathrm{CHC}(=0) N^{+} H_{2} C_{2} e_{2} C_{2} \mathrm{SO}_{3}{ }^{-}\right]_{n}-\mathrm{R}_{\mathrm{F}}$ (molecular weight of this oligomer cannot be determined because of the gel formation).

osilicate and the $\mathrm{R}_{\mathrm{F}}-(\mathrm{DOBAA})_{\mathrm{n}}-\mathrm{R}_{\mathrm{F}}$ oligomer in the silica gel matrices, and this affords nonflammability to the oligomer. Such effective interactions between ammonium hexafluorosilicate and the $\mathrm{R}_{\mathrm{F}}-(\mathrm{DOBAA})_{\mathrm{n}}-\mathrm{R}_{\mathrm{F}}$ oligomer in the silica gel matrices should enable the $\mathrm{R}_{\mathrm{F}}-(\mathrm{DOBAA})_{\mathrm{n}}-\mathrm{R}_{\mathrm{F}} /$ silica gel nanocomposite to have complete disappearance of the amido band of the $\mathrm{R}_{\mathrm{F}}-(\mathrm{DOBAA})_{\mathrm{n}}-\mathrm{R}_{\mathrm{F}}$ oligomer in the FT-IR spectrum measurements before and after calcination at $800{ }^{\circ} \mathrm{C}$. In fact, we have already reported that the ${ }^{1} \mathrm{H}$ MAS NMR spectra of the $\mathrm{R}_{\mathrm{F}}-(\mathrm{DOBAA})_{\mathrm{n}}-\mathrm{R}_{\mathrm{F}} /$ silica nanocomposite (with the oligomer content in the composite at $23 \%$, as determined by elemen- tary analyses of fluorine), which exhibit no weight loss even after calcinations at $800^{\circ} \mathrm{C}$, can exhibit similar relatively sharp peaks at around 50 to -20 p.p.m. ${ }^{17}$ These peak areas are almost the same as those before calcination at $800{ }^{\circ} \mathrm{C} .{ }^{17}$ Furthermore, it was previously reported that hexafluorosilicic acid can interact smoothly with amido segments in $\mathrm{N}, \mathrm{N}$-dimethylformamide to give a stable hexafluorosilicic acid-N,N-dimethylformamide $1: 3$ adduct. ${ }^{18,19}$ Thus, the surface of smoothly encapsulated $\mathrm{R}_{\mathrm{F}}-(\mathrm{DOBAA})_{\mathrm{n}}-\mathrm{R}_{\mathrm{F}}$ oligomer into silica gel nanomatrices through effective hydrogen bonding interactions of the amido protons in the oligomers and fluorines in ammonium 
hexafluorosilicate could possess an extraordinarily high oxidation resistance, explaining the exhibition of nonflammability during calcination at $800^{\circ} \mathrm{C}$.

We have prepared other fluoroalkyl end-capped oligomers/silica composites (with a theoretical content of each oligomer in the composites at $41 \%$ ) under the same conditions as those in Scheme 1 , and we have studied the thermal stability of these fluorinated oligomers/silica composites by the use of thermogravimetric analysis measurements, with results shown in Table 1.

As shown in Table $1, \mathrm{R}_{\mathrm{F}}-(\mathrm{NIPAM})_{\mathrm{n}}-\mathrm{R}_{\mathrm{F}}$ oligomer that possesses amido protons and $\mathrm{R}_{\mathrm{F}}-(\mathrm{DOBAA})_{\mathrm{n}}-\mathrm{R}_{\mathrm{F}}$ oligomer was found to exhibit no weight loss at $800{ }^{\circ} \mathrm{C}$ for the nanocomposite reaction under alkaline conditions, although the corresponding NIPAM oligomer/ silica composite prepared under acidic conditions exhibited clear weight loss at $800{ }^{\circ} \mathrm{C}$. In contrast, $\mathrm{R}_{\mathrm{F}}-(\mathrm{DMAA})_{\mathrm{n}}-\mathrm{R}_{\mathrm{F}}$ and $\mathrm{R}_{\mathrm{F}}-$ $(A C M O)_{n}-R_{F}$ oligomers (see Table 1, footnotes $d$ and e) that possess no amido protons were found to exhibit a clear weight loss behavior at $800{ }^{\circ} \mathrm{C}$, both for the nanocomposite reactions with silica nanoparticles under alkaline conditions and for the corresponding fluorinated oligomers/silica composites prepared under acidic conditions.

Not only fluoroalkyl end-capped acrylamide-type oligomers but also fluoroalkyl end-capped oligomers containing sulfo groups $\left[\mathrm{R}_{\mathrm{F}}-\right.$ $(\mathrm{MES})_{\mathrm{n}}-\mathrm{R}_{\mathrm{F}}$ ] formed by the nanocomposite reactions under alkaline conditions afforded no weight loss behavior at $800{ }^{\circ} \mathrm{C}$ (see Table 1 , footnote $\mathrm{f}$ ). However, fluoroalkyl end-capped oligomer containing carboxy groups $\left[\mathrm{R}_{\mathrm{F}}-(\mathrm{ACA})_{\mathrm{n}}-\mathrm{R}_{\mathrm{F}}\right]$ formed by the nanocomposite reaction has been already shown to exhibit a clear weight loss at $800^{\circ} \mathrm{C}$ (see Table 1,footnote $\mathrm{i}$ and $\mathrm{j}$ ). This interesting result could be due to the higher acidity of sulfo groups than carboxy groups in fluorinated oligomers, resulting in the smooth dehydrofluorination catalyzed by ammonia and silica nanoparticles. Therefore, the $\mathrm{R}_{\mathrm{F}}-(\mathrm{AMPS})_{\mathrm{n}}-\mathrm{R}_{\mathrm{F}}$ oligomer failed to accomplish such dehydrofluorination in composite reactions under alkaline conditions, affording no weight loss behavior, because this oligomer possesses betaine-type segments (see Table 1, footnote $\mathrm{k})$. Similarly, as the $\mathrm{R}_{\mathrm{F}}-(\mathrm{MACA})_{\mathrm{n}}-\mathrm{R}_{\mathrm{F}}$ oligomer possesses carboxy groups and $\mathrm{R}_{\mathrm{F}^{-}}(\mathrm{ACA})_{\mathrm{n}^{-}} \mathrm{R}_{\mathrm{F}}$ (see Table 1 , footnote $\mathrm{g}$ ), the $\mathrm{R}_{\mathrm{F}^{-}}$ $(\mathrm{MACA})_{\mathrm{n}}-\mathrm{R}_{\mathrm{F}}$ oligomer can exhibit a clear weight loss behavior by the composite reaction. However, interestingly, as the $R_{F^{-}}(M A C A)_{n}{ }^{-}$ (TFMA $)_{n}-R_{F}$ co-oligomer possesses a higher number of acidic carboxy groups than the $R_{F}-(M A C A)_{n}-R_{F}$ oligomer due to the presence of electron-withdrawing $\mathrm{CF}_{3}$ groups in the co-oligomer, this fluorinated co-oligomer is expected to exhibit no weight loss behavior at $800{ }^{\circ} \mathrm{C}$ for the composite reaction. ${ }^{20}$ In fact, we have succeeded in observing no weight loss behavior for this composite at $800^{\circ} \mathrm{C}$ (see Table 1, footnote $\mathrm{h}$ ).

In conclusion, these experiments show that fluoroalkyl end-capped oligomers containing amido protons or more acidic protons, such as sulfo groups and carboxy groups, possessing electron-withdrawing $\mathrm{CF}_{3}$ units as neighboring groups can be used as novel fluorinated functional materials possessing a perfectly nonflammable characteristic at $800{ }^{\circ} \mathrm{C}$ for the composite reactions with silica nanoparticles. In particular, fluorinated oligomers containing amido protons should enable the smooth dehydrofluorination of amido protons with fluorines in oligomers catalyzed by ammonia and silica nanoparticles, affording ammonium hexafluorosilicate with the effective interaction of amido groups and hexafluorosilicate anions, although the amido protons generally exhibit an extremely weak acidity compared with that of the sulfo and carboxy groups. Thus, this unique technology can result in new developments for oxidation-resistant functional materials in a wide variety of fields.

1 Dolbier, W. R. Jr. Fluorine chemistry at the millennium. J. Fluorine Chem. 126, 157-163 (2005).

2 Scheirs, J. (Ed.) Modern Fluoropolymers (Wiley, Chichester, 1997).

3 Ameduri, B. \& Boutevin, B. Well-Architectured Fluoropolymers: Synthesis: Properties and Applications (Elsevier, Amsterdam, 2004).

4 Johns, K. \& Stead, G. Fluoroproducts-the extremophiles. J. Fluorine Chem. 104, 5-18 (2000).

5 Ameduri, B. \& Boutevin, B. Copolymerization of fluorinated monomers: recent developments and future trends. J. Fluorine Chem. 104, 53-62 (2000).

6 Chen, Y. -C., Tsai, C. -C. \& Lee, Y. -D. Preparation and properties of silylated PTFE/SiO organic-inorganic hybrids via sol-gel process. J. Polym. Sci.: Part A: Polym. Chem. 42, 1789-1807 (2004).

7 Harmer, M. K., Farneth, W. E. \& Sun, Q. High surface area nafion resin/silica nanocomposites: a new class of solid acid catalyst. J. Am. Chem. Soc. 118, 7708-7715 (1996).

8 Cho, J. -W. \& Sul, K. -I. Crystallization of poly(vinylidene fluoride)- $\mathrm{SiO}_{2}$ hybrid composites prepared by a sol-gel process. Fibers and Polymers 2, 135-140 (2001).

9 Yano, S., Okubo, N. \& Takahashi, K. Physical properties of sol-gel derived poly(vinylidene fluoride)/silica hybrid. Macromol. Symp. 108, 279-289 (1996).

10 Fabbri, P., Messori, M., Montecchi, M., Nannarone, S., Pasquali, L., Pilati, F., Tonelli, C. \& Toselli, M. Perfluoropolyether-based organic-inorganic hybrid coatings. Polymer 47, 1055-1062 (2006).

11 Ansari, S. \& Giannelis, E. P Functionalized graphene sheet-poly(vinylidene fluoride) conductive nanocomposites. J. Polym. Sci. Part B: Polym. Phys. 47, 888-897 (2009).

12 Sawada, H., Yoshino, Y., Kurachi, M., Kawase, T., Takishita, K. \& Tanedani, T. Recognition of hydrophilic amino and $N, N$-dimethylamino compounds by the selfassembled aggregates of fluoroalkylated end-capped $\mathrm{N}$-(1,1-dimethyl-3-oxobutyl)acrylamide oligomer. Polymer 41, 397-400 (2000).

13 Sawada, H., Narumi, T., Kodama, S., Kamijo, M., Ebara, R., Sugiya, M. \& Iwasaki, Y. A fluoroalkyl end-capped $\mathrm{N}$-(1,1-dimethyl-3-oxobutyl)acrylamide oligomer/silica gel nanocomposite with no weight loss even at $800^{\circ} \mathrm{C}$ equal to an original silica gel. Colloid Polym. Sci. 285, 977-983 (2007).

14 Sawada, H., Tashima, T. \& Kodama, S. Preparation of a variety of fluoroalkyl endcapped $\mathrm{N}$-(1,1-dimethyl-3-oxobutyl)acrylamide oligomer/silica nanocomposites possessing no weight loss characteristic at $800^{\circ} \mathrm{C}$. Polym. Adv. Technol. 19, 739-747 (2008).

$15 \mathrm{Kao}, \mathrm{H} .-\mathrm{M}$. \& Chen, Y.- C. ${ }^{27} \mathrm{Al}$ and ${ }^{19} \mathrm{~F}$ Solid-state NMR studies of zeolite H- $\beta$ dealuminated with ammonium hexafluorosilicate. J. Phys. Chem. B 107, 3367-3375 (2003).

16 Kao, H. -M. \& Chang, P .-C. Direct solid-state NMR spectroscopic evidence for the $\mathrm{NH}_{4} \mathrm{AlF}_{4}$ crystalline phase derived from zeolite $\mathrm{HY}$ dealuminated with ammonium hexafluorosilicate. J. Phys. Chem. B 110, 19104-19107 (2006).

17 Sawada, H., Kakehi, H., Tashima, T., Nishiyame, Y., Miura, M. \& Isu, N. Fluoroalkyl end-capped oligomer possessing a nonflammable characteristic in silica gel matrices even at $800^{\circ} \mathrm{C}$ under atmospheric conditions. J. Appl. Polym. Sci. 112, 3482-3487 (2009).

18 Yoshimura, C. \& Miyamoto, M. Nonaqueous conductimetric titration of alkaline earth metals and aluminum with hexafluorosilicic acid- $N, N$-dimethylformamide adduct. Bunseki Kagaku 29, 829-833 (1980).

19 Yoshimura, C. \& Hujino, T. Nonaqueous conductimetric titration of molybdenum with hexafluorosilicic acid, $\mathrm{N}$ - $\mathrm{N}$-dimethylformamide adduct. Bunseki Kagaku 33, 48-53 (1983).

20 Piletska, E. V., Guerreiro, A. P., Romero-Guerra, M., Chianella, I., Turner, A. P. F. \& Piletsky, S. A. Design of molecular imprinted polymers compatible with aqueous environment. Anal. Chim. Acta. 607, 54-60 (2008): This paper shows that the $\mathrm{p} K_{\mathrm{a}}$ of monomers (their polymers) of 2-trifluoromethacrylic acid, methacrylic acid and acrylic acid are 2.7 (5.7), 4.65 (6.7) and $4.25(6.6)$, respectively. 